\title{
Ability of Architects to See Autopoietic Environmental Features
}

\author{
Vytautas Petrušonis* \\ Vilnius Gediminas Technical University, Vilnius, Lithuania
}

Received 2020-09-10; accepted: 2021-05-12

\section{Keywords}

Autopoiesis, autopoietic environmental features.

\begin{abstract}
This article discusses the way of rating the competency of architects through their ability to recognize the autopoietic properties of architecture in developed urban projects. The following theoretical methods were used: abstraction, analogy, generalization and reasoning. Metalanguage of consideration (opposite to directive metalanguage) embedded in projects displays the fact, that a person is able to recognize such autopoietic features as connotations, memory traces, that are important for continuity of locus cultural identity.
\end{abstract}

\section{Introduction}

The way architects now are considering, seeing the world of architectural problems, is a serious obstacle preventing them from unfolding their creativity in work with the historic urban environment. It is often because of the classical worldview relics still remaining in thinking. An understanding of the autopoietic features of architecture itself related with the rise of non-clasical paradigm may help to get rid of outdated views. In order to perceive autopoietic qualities, a certain level of person's (whether it is an architect, an official, or a member of public) competency is required (competence may be acquired, while the competency may be developed). In order to recognize these qualities, education of architects should be based on non-classic and sinergetic paradigm.

The aim of the article is to present the criteria for assessing the level of cultural and ecological competency of architects considering their ability to recognize the autopoietic properties of architecture. The following tasks were set: 1) to review the idea of autopoiesis; 2) to distinguish and disclose peculiarity of two thinking modes that are based both on classical world view and on the non-classical view; 3) to discuss the autopoietic features of architecture; 4) to propose criteria for evaluating capability to recognise autopoietic features by architects, to discuss examples of competency evaluation.
In elaboration of knowledge presented in this article, the following theoretical methods were used: abstraction, analogy, generalization, reasoning (inductive, deductive, abductive), analysis and synthesis.

\section{The Idea of Autopoiesis}

A new approach in cognitive science, developed by Francisco Varela and his colleagues, was called emergence or connectionism [1], [2]. It was based on a concept that tasks related with seeing and memory are better handled when a system has been set of simple components connected according certain rules. It was found that such system can better generate global behaviour appropriate to the aspired task. This view underlines the network quality of systems and the spontaneous emergence of global patterns - when the states of all engaged components achieve a commonly satisfactory state, without the need for a central processing unit to navigate the entire operation [3, 243, 244].

Nonetheless, Varela finds the limits of connectionism. It still asserts that cognition is a successful representation of an external world which is pregiven. Soon he argumented that external world is "not pre-given, but enacted or brought forth from a background, and what counts as relevant is what our common-sense sanctions as such, always in a contextual way" [3,250,251]. Varela calls his own approach 
enactive cognitive science [1]. This approach arose from the theory of autopoiesis that he developed with H. Maturana [4], [5].

The word autopoiesis refers to self-producing or selfmaking and is used by Maturana and Varela to be attributed to the 'organization of the living' and to the basic definition of what describes a biological entity as being 'alive' [5]. The most compelling feature of an autopoieitic system is that it brings itself up by its own 'bootstraps' (it means - get oneself into or out of a situation using existing resources) and becomes evident from its environment through its own dynamics in such a way that both things are inseparable [6].

According to the concept of autopoiesis living beings are autonomous unities [5, 47]. R. Hallowell, presenting the contribution of Varela and Maturana, explains: "Theory of autopoiesis demonstrates how biological entities, through the organization of their components, self-produce the structures that define them as living beings and how they interact with their environment through, what they call, structural coupling" [6, 149]. According to Maturana and Varela, "Structural coupling $<\ldots>$ is a history of recurrent interactions leading to the structural congruence between two (or more) systems" [5, 75]. The structural coupling between systems is constrained by the inner structure of the autopoietic entity [6, 149].

Humberto Maturana and Francisco Varela argue that one of the most crucial features of an autopoietic system is its operational closure [5]. The definition of operational closure states that "system maintains its organization, structure and integrity in the face of perturbations from the environment" $[6,149]$. According to Maturana and Varela: "The $<\ldots>$ system's organization is a network of active components in which every change of relations of activity leads to further changes of relations of activity. Some of these relationships remain invariant through continuous perturbation both due to the <... > system's own dynamics and due to the interactions of the organism it integrates. In other words, the $<$... > system functions as a closed network of changes in relations of activity between its components" [5, 164].

Ronan Hallowell states: "This does not mean that the $<\ldots>$ system does not have plasticity or that it is not affected by its interaction with the environment. The operational closure of the $<\ldots>$ system preserves the organization of the components that comprise it and allows it to remain intact while it on-goingly interacts with the environment. If it did not maintain this organization and structure, then it would cease to exist as an autopoietic entity that is alive" $[6,150]$.

According to N. Katherine Hayles, based on various studies, Maturana concluded that perception is not fundamentally representational $[7,137]$. There must be a clear understanding that the world we perceive is first of all a result of the structure of our brain and nervous system and only then the result of our structural conjunction with other organisms and our environment $[6,151]$. Following this idea Hallovell, Maturana and Varela developed the theory of autopoiesis based on their concept regarding cognition, structural conjunction, language, societies, ethics, and the biology of love $[6,152]$. The capacity of human love allows individuals to collaborate and create a common area of cognition. It all emphasizes the importance of acceptance of other subjectivities with empathy.

\section{The Limitations of Classical Worldview and Useful Peculiarities of the Non-Classical View}

The change in the general scientific worldview is usually accompanied by a fundamental change in the normative structures of research. Classical rationality focuses on the object, on a theoretical level seeks to distance itself from everything related to the subject, his means of acting and actions itself. Non-classical and post-non-classical rationality, in its turn, considers the relationship between knowledge of an object and assesses the nature of the means of actions and also their relation with values and goals [8, 32], [9, 619].

The known from Ancient Greece idea of separating subject and object has been criticized not only by the creators of the theory of autopoetics but also by the proponents of the non-classical paradigm. M. Mamardasvili was explaining that the object in classical knowledge is understood on the base of the the principle of spatiality, i.e., with the requirement of complete spatial articulation of the object outside of itself (and accessible to external observation) as a condition of what we can know about it scientifically [10]. According to S. Vladiv-Glover, sign in this case is transparent to meaning [11].

According to Mamardashvili, classical ontology does not rely on transformations - classical science does not recognize any discontinuities within the the field of perception [10]. In the classical approach, the observer can only understand things if he knows or remembers something. In reality, understanding is not based on any external causality, it is not fundamentally separated from the object being observed.

Understanding is not based on causality; it emerges as a spark. Mamardashvili explains what is understanding by giving as example a feeling of love. Who has not experienced love cannot understand what it is [10].

Very important in Mamardashvili teaching is the change of a 'physical fact' into an 'event' or 'fact' of consciousness. This process constructs a new kind of knowledge [10]. As Mamardashvili says, while the 'reduction', conceived as a mode of being, is an 'abstract procedure', the phenomenon possesses a definite materiality or 'textuality'. Thus, the phenomenon is a configuration of consciousness that "possesses a sensory texture which emerges as a localized expression of an invisible totality. For example, a 'sound 
as a phenomenon of music is not a sound-phenomenon"' (citation from Vladiv-Glover translation [11]).

The phenomenon is, according to Mamardasvili, an index of the 'materiality' of consciousness. Vladiv-Glover writes that Mamardasvili has cited the symptom (of Freudian psychoanalysis) as a good example of a phenomenologically reduced phenomenon which demonstrates the 'physical' or 'corporeal' aspect of consciousness. It is very important that the symptom, in fact, is a displaced identity, irreducible and not identical with itself, that points to something else or that gives expression to something that is 'other' [11].

The phenomenological objects of consciousness, in Mamardashvili conception, contrary to the classical external objects of observation, have something 'internal' 'capacity' to keep local information that can extend to heterogeneous regions of consciousness [10]. Through the exclusion of the sphere of being, the phenomena of the world are decreased to the 'pure' phenomena which Mamardasvili calls 'conscious objects' or 'objects of consciousness' [10]. 'Objects of consciousness' (phenomenologically reduced phenomena) in S. Vladiv-Glover opinion can be assumed as equivalents of the memory trace (namely, she offered to use this Freudian concept) [11].

\section{Autopoietic Features of Architecture}

P. Shummacher's book "The Autopoiesis of Architecture" [12], [13] testifies the fact that the author understands the idea of autopoiesis too superficially. Both volumes reflect the classical paradigm. Talking about fundamental aspects of autopoietic systems - autonomy (operational closure) and structural coupling, it seems that Schumacher, regarding the first one, is overemphasizing the autonomy of architecture and underestimating the role of sociocultural memory. Further, regarding the second aspect structural coupling - his concept greatly weakens the focus of the vital relationships with the environment. So, the significance of the wider context in shaping architecture objects is neglected.

Shumacher's proposed style of parametricism, which attempts to be based on the idea of autopoiesis, was rightly criticized. Some critics have explained that this is just a failed attempt to change modernism. "In describing this new kind of recently emerged architectural formalism, Patrik Schumacher went as far as to call it a new epochal style, globally replacing Modernism and its offsprings $[14,358]$. According to Samalavičius, "as a discourse and practice, it is an 'avatar' of globalization contributing to the homogenization of urban environments" [14, 355]. G. McKay expressed his opinion about Shumacher's book as follows: "If you do read it, I doubt you'll be convinced Parametricism is the way architecture should be" [15].

Architecture of the whole, also a separate project, certain urbanised places themselves are autopoietic systems. The memory traces associated with them can be treated as the nodes of network needed for autopoietic system that make up the system itself.

Recent articles [16] and [17] discuss autopoietic systems while discussing the issues of historical environment management, considering the most appropriate form of structure of the place identity code, in connection with the non-classical paradigm. Namely such elements of code as 'objects of consciousness' (in other words, 'intelligent bodies'), as shifters and connotational semantic units, are important for orienting creational activity regarding respect to locus cultural identity. Today, notion 'memory traces' has been added as partial synonyme to this collection.

\section{Evaluation of Architects' Capability to Recognise Autopoietic Features}

It is possible to determine whether a person is capable to recognize the features of the autopoietic system by use of criteria of the manifestation of the metalanguage embodied in the text of 'practical considerations'. For this reason, practical considerations need to be analysed all documents about planned activities regarding the future of object (articles, reports of expertise, reviews, legal documents, also urban and architectural designs) generated by certain person or group.

There is a need to watch what type of metalanguage is embedded in practical considerations on a higher scale. Metalanguage is any language or symbolic system used to discuss, describe, or analyze another language or symbolic system (as language-object). For example, in the law regulating the protection of cultural heritage, the concept of protection of the historical environment, the interpretation of preservation will be a language-object, and the measures conditioning the process of protection presented in legal language will belong to the level of metalanguage.

The possibility to assess a wider context is ensured by the structural features of the text - the type of embedded metalanguage. Metalanguages as a structural element of legal regulations can be of two types. One of them can be called the directive metalanguage, and the othermetalanguage of consideration.

If metalanguage of consideration is more expressed, there is a possibility for more viable solution. Only in such case we will see items that F. Varela and H. Maturana call the nodes of the network that create the system itself in the process of self-creation. The metalanguage of consideration presenting connotations as memory traces as shifters is open to the context, it gives you possibilities to have insight into the newly emerged, additional information, the results of new research or fresh information about a certain city part. The memory traces can be presented only 
by this type of metalanguage. The most important here is the information that is carried by memory traces as shifters. This enables switching the designer's thinking to another mode of life and being that contains memory.

In the directive metalanguage, the requirements are formulated in direct absolute statements, and the depth of knowledge generation is particularly small. Regulation of activities based on this metalanguage does not create conditions for dialogue with the place, with the subjectivity inherent in it.

If someone operates with consideration metalanguage, then it can be stated that this certain person is able to recognize the autopoietic features of architecture. That is, the person has a sufficient level of cultural-ecological competency, he is capable to accept the other subject emphatically.

A description of a cultural identity of locus must be done indirectly - using the metalanguage of consideration. In such case building construction code of certain territory can be understood as the set of determinants of genius loci, expressed as a set of symptoms, shifters (for more detail see [9]). Very important requirement for the description of locus identity - denotative and connotative semantic units - have to be presented together.

The example of detailed plan of Paupys in Vilnius in the territory of former Skaiteks factory (Detailed Project Plan for T-4 Block in the Territory between Maironio, Aukštaičių, Paupio, Zarasų and Polocko Streets in Vilnius; Vilniaus Planas company, 2012, project manager A. Alūzienè, architect M. Pakalnis) shows how activities of authors can be interpreted from the point of view recognising the autopoietic features of a place. The results of evaluation of the detailed plan itself were published in 2013 [18] and 2018.

The detailed plan of Paupys ignored the fact that this place for a long time had industrial character. The authors of the plan limited themselves to such features of blocks as 'structures, similar to circumferential buildings', 'smaller constructions at the embankment', 'clearly expressed

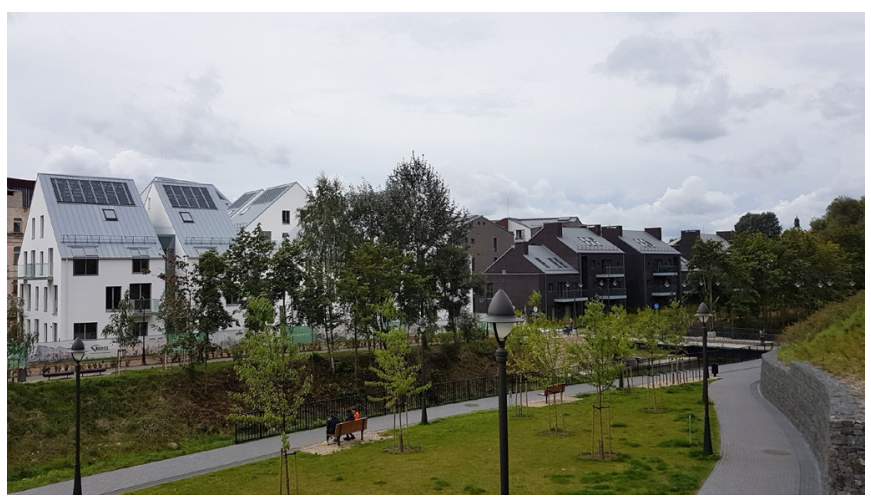

Fig. 1. New architecture of district Paupys, Vilnius (photo taken by Vytautas Petrušonis, 2020). public spaces - the street area, embankment, square', 'closed and semi-closed yard spaces', 'closed and semiclosed inner courts', 'yard structure, characteristic of the old-town', 'circumferential and city villa construction principles'. A set of such description units has an exclusively denotative character. Connotative characterisation is absent. The mentioned features are common for many cities. In description there are no signs of characteristic features of place - no symptoms of historically grounded genius loci and, thus, no memory traces.

So, the metalanguage of the detailed plan of Paupys is a directive metalanguage. Anyway, architects who designed groups of buildings on the basis of a detailed plan created aesthetically valuable compositions, although, unfortunately they reflect the globalist trend. Of course, it conveys the character of a generalized European city architecture, but there is no connection with location. Although the aesthetic quality of architecture cannot be denied, it is pity that the architects did not even try to base it on local memory (Fig. 1).

Paupys is just one case - in Vilnius there are several other such resonant examples criticized in the press. We also see such sort of manifestations of new architecture in Kaunas. For example, the new Bussiness Centre on the embankment of river Nemunas (Fig. 2). In the examples in Vilnius (Paupys) and Kaunas (Bussiness Centre), no memory traces of place were studied before the projects were prepared.

Of course, the Lithuanian legislation acts governing the management of the historic urban environment are also to be blamed for this [19], [20]. An analysis of various legal documents has shown that today urban regulation in Lithuania and also the interpretation of architectural text is based on contextually closed directive metalanguage. Using the criteria of metalanguage type we can conclude that the mentioned legislation acts are not friendly to historic places.

Thus, the several cases presented here (selected as typical) testify that architects do not fully understand

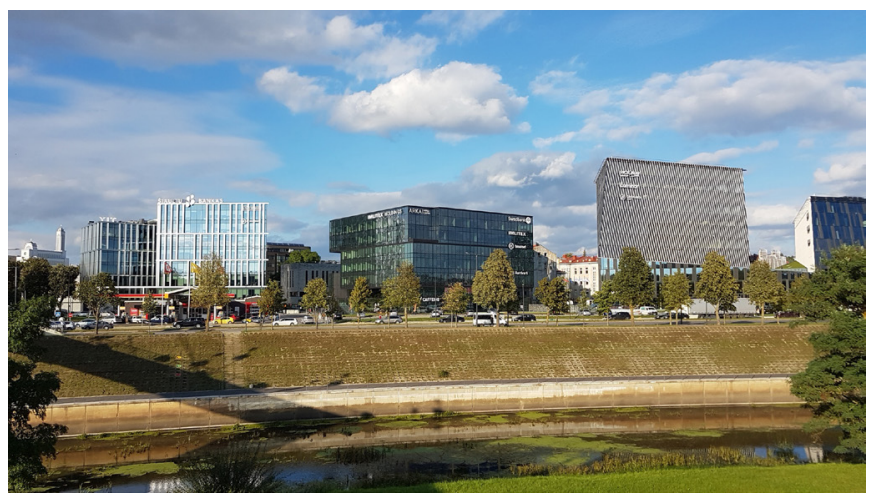

Fig. 2. New Bussiness Centre on the embankment of river Nemunas, Kaunas (photo taken by Vytautas Petrušonis, 2020). 
the role of socio-cultural memory in the creation of new architectural objects. This means that they are looking at the environment without empathy. Because an activity can have empathic character only in the case of operating with metalanguage of consideration, and by no means of directive metalanguage. Meanwhile, from the point of autopoiesis concept the activities of architects are belonging to active components of environment functioning of which can guarantee the continuity of architecture. And for that, architects must be able to recognize traces of memory and to take them into account in their creative activities.

\section{Conclusions}

1. For a deeper understanding of the creative problems of architecture, it is appropriate to consider the possibilities provided by the theory of autopoiesis. The idea of autopoiesis based on the self-creation of alive systems in more illustrative way presents the essence of the dynamic system whose change is selfmanaged owing to the features of internal structure and certain autonomy, without some central control unit. Such view underlines the spontaneous nature of autopoietic systems that create themselves through the organization of their components, which in turn produce the structural elements of system itself.

2. Autopoietic systems related with the field of architectural activity are those systems that, as a whole, are determined by the network of that components creating system. The components on a base of the feedback, through interactions (with participation of people - architects, politicians and public in general) generate and implement a network that lets constantly (re)create the architectural environment itself as an autopoietic system. For historic parts of the city memory traces are important parts of such components - as nodes of conceptual network that enable to respect genius loci (cultural identity of locality).

3. At present, although there are attempts in modern architectural theory to take into account the principles of autopoiesis, they are understood too superficially; the principle of autonomy of architecture is overestimated, at the same time in relation with environment the role of socio-cultural context of architecture is rather diminished.

4. The degree of understanding of the mentioned autopoietic aspects is not satisfactory, because the acquiring of 'classic' knowledge prevails in the education of architects and in general. Both external and internal self-control of architects play an important role in developing their ability to recognize the autopoietic properties of architecture. Disclosing of abilities that in a consolidated way exposes the degree of one's own or others' cultural-ecological competency and the depth of strategic thinking is an important step towards appropriate changes in thinking.

5. Method of finding the type of metalanguage embedded in the text (any program, vision or project) is the main point of this article. Metalanguage of consideration contrary to the directive metalanguage can stimulate creative thinking. The results of testing various actual documents allow to show how a paticular architect (or other person) sees and perceives the determinants of identity, the possibilities of change of historical environment; is he able or not to read memory traces. The ability adequately (from practical point of view) cognize relevant architectural issues is inseparable from the ability to recognize the autopoietic features of an architectural object and architectural environment in general.

\section{REFERENCES}

1. Varela, F., Thompson, E., Rosch, E. The embodied mind: Cognitive science and human experience. Cambridge, MA: MIT Press, 1993. 328 p.

2. Ward, D. Silverman, D. Villalobos, M. Introduction: The Varieties of Enactivism. Topoi, Vol. 36, 2017, pp. 365-375. https://doi.org/10.1007/s11245-017-9484-6

3. Varela, F. Whence perceptual meaning? A cartography of current ideas. In F. Varela \& J. P. Dupuy (Eds.) Understanding origins: Contemporary views on the origins of life, mind and society. Springer, Dordrecht, 1992, pp. 235-263. https://doi. org/10.1007/978-94-015-8054-0_13

4. Maturana, H., Varela, F. Autopoiesis and Cognition: The realization of the living. Dordrecht: D. Reidel Publishing Co, 1980. 146 p. https://doi.org/10.1007/978-94-009-8947-4

5. Maturana, H., Varela, F. The tree of knowledge: The biological roots of human understanding. Boston: Shambhala, 1992. 269 p.

6. Hallowell, R. Humberto Maturana and Francisco Varela's Contribution to Media Ecology: Autopoiesis, The Santiago School of Cognition, and Enactive Cognitive Science. Proceedings of the Media Ecology Assocation, Vol. 10, 2009, pp. 143-158.

7. Hayles, N. K. How We Became Posthuman: Virtual bodies in Cybernetics, Literature, and Informatics. Chicago: University of Chicago Press. 1999. 364 p. https://doi.org/10.7208/ chicago/9780226321394.001.0001

8. Arshinov, V. I., Lepskij, V. E. (Eds). Problemy subjektov v postneklassicheskoj nauke. Moskva: Kogito-Centr, 2007. $272 \mathrm{p}$.

9. Stepin, V. S. Teoreticheskoe znanie. Moskva: Progress Tradicija, 2003.393 p.

10. Mamardashvili, M. Klassicheskij i neklassicheskij idealy racionalnosti. Moskva: Logos, 2004. 288 p.

11. Vladiv-Glover, $\mathbf{S}$. What is classical and non-classical knowledge? Studies in East European Thought, Vol. 58, 2006, pp. 205-238. https://doi.org/10.1007/s11212-006-9004-5 
12. Schumacher P. The Autopoiesis of Architecture, Volume I: A New Framework for Architecture. New York: Wiley, 2011. $478 \mathrm{p}$.

13. Schumacher P. The Autopoiesis of Architecture, Volume II: A New Agenda for Architecture. New York: Wiley, 2012. 784 p.

14. Samalavičius, A. Ideology as Geometry: A note on Parametricism and its theoretical foundations. Symmetry: Culture and Science, Vol. 31, No. 3, 2020, pp. 353-364. https:// doi.org/10.26830/symmetry_2020_3_353

15. McKay, G. The Autopoiesis of Architecure Vol. I (review) [online]. misfits' architecture [cited 5.08.2020]. https:// misfitsarchitecture.com/2018/07/29/the-autopoiesis-ofarchitecure-vol-1/.

16. Petrušonis, V. Methodological Perspectives of Evaluation of Cultural Heritage in The Context of Changing Scientific Paradigms. Journal of Architecture and Urbanism, Vol. 36, No. 1, 2012, pp. 1-8. https://doi.org/10.3846/20297955.2 012.679772

17. Petrušonis, V. Conditions for a dialogue of local community and genius loci. Architecture and Urban Planning, Vol. 14, Issue 1, 2018, pp. 70-74. https://doi.org/10.2478/aup-20180009

18. Petrušonis, V. Urbanistinè renovacija ir kultūriniai archetipai [online]. Spec.lt [cited 05/10/2018]. https:// www.spec.lt/straipsniai/urbanistine-renovacija-irkulturiniai-archetipai.

19. Ministry of Culture of the Republic of Lithuania. Description of filling in the form of the act of the immovable cultural heritage assessment council (approved by the Director of the Department of Cultural Heritage under the Ministry of Culture of the Republic of Lithuania in 12/10/2020, order No. I-272), = Nekilnojamojo kultūros paveldo vertinimo tarybos akto formos pildymo aprašas, in Lithuanian, [interactive], accessed 02/12/2020. https://eseimas.lrs.lt/portal/legalAct/lt/TAD/TAIS.404018/asr

20. Minister of Culture of the Republic of Lithuania. Description of the criteria for the assessment, selection and determination of the level of significance of immovable cultural property (approved by the Minister of Culture of the Republic of Lithuania in 4/10/2016, order No İV-150), = Nekilnojamųjų kultūros vertybių vertinimo, atrankos ir reikšmingumo lygmens nustatymo kriterijų aprašas, in Lithuanian, [interactive], accessed 02/12/2020. https://eseimas.lrs.lt/portal/legalAct/lt/TAD/TAIS.254663/asr

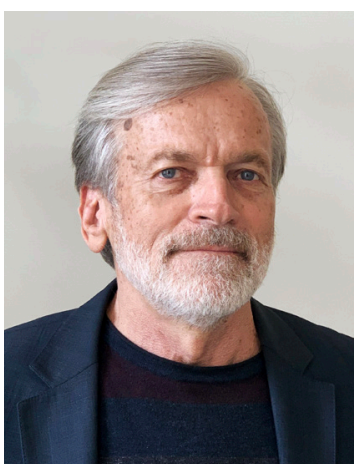

Vytautas Petrušonis obtained a degree of Doctor of the Humanities (architecture) from VGTU in 2005. He is an author or co-author of 16 architectural design projects and 12 projects of territory planning. Vytautas Petrušonis is the author of 13 scientific research reports, 53 scientific and critical articles. He is currently an Associate Professor with the Department of Architectural Fundamentals, Theory and Art of Vilnius Gediminas Technical University (VGTU). He is a member of Lithuanian Union of Architects and of Association ICOMOS Lithuania. His research interests are cultural identity of place, structural and typological features of architectural objects, architecture and psychology, ethics of architect, creative thinking of architect, metacritical analysis of architectural activity.

\section{Contact Data}

\section{Vytautas Petrušonis}

Department of Architectural Fundamentals, Theory and Art of Vilnius Gediminas Technical University Address: 26/1 Pylimo St., Vilnius, 01132, Lithuania E-mail: vytautas.petrusonis@vgtu.lt 